\title{
Opinion of Speech Language Pathologist/Therapist about Common Communication and Swallowing Difficulties in Children with Cerebral Palsy
}

\section{Rabbiya Imtiaz', Hafsa Noreen², Atia ur Rehman³, Muhammad Sikander Ghayas Khan4, Nayab Iftikhar ${ }^{5}$, Saba Yaqoob 6}

${ }^{1}$ Speech Language Pathologist, Services Hospital, Lahore

${ }^{2}$ Assistant Professor, Department of Health Professional Technology, The University of Lahore, Lahore ${ }^{3}$ Assistant Professor, Department of Health Professional Technology, The University of Lahore, Lahore

${ }^{4}$ Associate Professor, Department of Health Professional Technology, The University of Lahore, Lahore

${ }^{5}$ Assistant Professor, Department of Speech Language Pathology, The University of the Punjab, Lahore

${ }^{6}$ Senior Lecturer, Department of Allied Health Sciences, Nur International University

\begin{abstract}
Author's Contribution
1-2Conception and design, Collection and assembly of data, ${ }^{3}$ Drafting of article, Analysis and interpretation of the data, ${ }^{4-6}$ Critical revision of the article for important intellectual content, ${ }^{4}$ Statistical expertise ${ }^{3}$ Final approval and guarantor of the article.
\end{abstract}

Article Info.

Received: March 3, 2020

Acceptance: Nov 29, 2021

Conflict of Interest: None

Funding Sources: None

Address of Correspondence

Hafsa Noreen

Email Id: virgo202001@yahoo.com

ORIC Id: 0000-0002-7933-186X

Cite this article as: Imtiaz R, Noreen

$H$, Rehman AU, Khan MSG, Iftikhar

N, Yaqoob S. Opinion of Speech

Language Pathologist/Therapist

about Common Communication and

Swallowing Difficulties in Children

with Cerebral Palsy. JRCRS. 2021;

9(2):66-70.

DOI: $\underline{10.53389 / J R C R S .2021090206}$

\section{A B S T R A C T}

Background: Children with cerebral Palsy experiences variety of speech, language and swallowing difficulties. The nature and severity of these difficulties depends upon the type of motor impairment diagnosed in each child.

Objective: To find out the opinion of speech pathologists/therapists regarding the common communication difficulties in children with cerebral palsy.

Methodology: The study included 212 speech language therapists. Respondents were BS, MS and diploma holders with the experience of 1 year or more dealing with children with cerebral palsy. Data was collected using a questionnaire developed by Literature Review and Expert Opinion Using Content Validity Index. It constituted 21 questions on different aspects of speech, language, and swallowing difficulties to gain therapists' opinion on the frequency of specific difficulties observed in their interactions with children having cerebral palsy. For results, Frequency and Percentages were calculated of the responses.

Results: Results indicated that Children with $\mathrm{CP}$ has problem in attention deficit, Problem understanding words, writing difficulties, have Orofacial weakness and also have articulation problems.

Conclusion: It is concluded that the Children with CP have communication and swallowing difficulties associated with impairments in oral motor function, expression and comprehension, and the functioning of oral and pharyngeal swallowing stages in children with cerebral palsy.

Keywords: Cerebral Palsy, Oral Motor Functioning, Pathologist, Expression, Comprehension, Deglutition

\section{Introduction}

Cerebral Palsy refers to a group of non-progressive disorders characterized by neuromata impairment of varying severity. The prevalence of $\mathrm{CP}$ as evaluated by most recent surveys has been reported to be 2.11 per 1,000 live births. The prevalence has stayed steady over the ongoing decade, notwithstanding the expanded endurance of in danger preterm infants. ${ }^{1}$ The etiology of CP includes various prenatal, perinatal and post natal factors such as birth asphyxia, prolonged labor, and premature birth, infections like rubella, toxoplasmosis, cytomegalovirus, and meningitis. On the basis of main movements impaired, there are four major types of cerebral palsy: spastic, dyskinetic, ataxic, and mixed. ${ }^{2}$ Contingent upon 
the key areas affected, these issues are evident in the corresponding types: Firm muscles (spasticity), Wild developments(dyskinesia), Poor equalization and coordination (ataxia).There are also other related conditions that occur with $\mathrm{cp}$ in children, for example, scholarly handicap, seizures, issues with vision, hearing, or discourse; changes in the spine or joint issues. $^{3}$

As cerebral palsy causes the disturbance in neuromotor functioning, there is a disruption in the normal patterns of perception, sensation and cognition in addition to the impaired movements; as a result children also experience problems with deglutition, especially in the oral and pharyngeal stages of swallowing. ${ }^{4}$ These difficulties in the normal process of swallowing result in feeding problems characterizing the disorder called dysphagia. This is mostly due to the neurological disruptions that cause sensory impairment generating poor sensorimotor control during various stages of swallowing. Poor oropharyngeal sensation causes delayed swallow initiation, which in most cases cause aspiration of food and fluids into the airways, resulting in conditions like pneumonia which is a major health risk in such patients. Due to the high risk of aspiration in these cases, feeding is normally limited and through alternative means that have lower risk of aspiration. ${ }^{5}$ However, nutritional deficiencies are commonly reported even with the alternative means of feeding adopted which results in poor health indicators in Children with CP. An interdisciplinary team skilled in assessing and managing these characteristic abnormalities of children with cerebral palsy must be throughout in access of the families with such children to prevent the above mentioned repercussions of this disorder because of the life threatening complications associated with those repercussions. Moreover, the expected nutritional deficiencies associated with the swallowing abnormalities further intensify the already intense problems in neuromotor and cognitive development, further deteriorating the abilities to learn and develop skills in the areas of speech and language. ${ }^{6}$

Communication profile of children diagnosed with nearly all types of children indicates the presence of communication impairments. As functional communication involves use of both receptive and expressive modes in the form of speech and language, children with cerebral paralysis encounter challenges with correspondence in zones, for example, discourse, the improvement of signal and outward appearance, responsive and expressive language and voice creation. ${ }^{10}$ Cerebral paralysis can influence the regions concerned with language processing in the brain, bringing about trouble with semantics or word retrieval issues impeding the child to use proper expression. The main challenges in these aspects as reported by various sources are speech problems concerning respiration, phonation, resonance, and articulation limitations associated with poor motor control and muscle weakness. ${ }^{11}$

According to a research, children with cerebral palsy have limited utterances and minimum mean length of utterances. Because of the respiratory insufficiency present in most of the cases, these children do not produce multisyllabic utterance; instead monosyllabic utterances are produced. These characteristics frame the presence of dysarthria in Children with $\mathrm{CP}$, which has further four types that correlate with the four types of cerebral palsy, namely: spastic dysarthria, flaccid dyarthria, ataxic dysarthria, and mixed dysarthria, and the parameters of dysarthria include all five of the speech subsystems which are: articulation, phonation, respiration, prosody and resonance. ${ }^{13}$

Speech and language pathologists or therapists serve an instrumental role in providing communication and swallowing intervention to individuals with cerebral palsy and they are an integral part of the interdisciplinary team working with cerebral palsy. Speech language therapy assists such children in developing functional speech and language skills and normal swallow patterns by working the spheres of respirationphonation coordination, articulation, resonance and language development. Thereby, they possess detailed knowledge of characteristic features of difficulties in these domains found in cerebral palsy affected children. ${ }^{14} \mathrm{~A}$ study of the opinion of speech and language pathologists on the frequency of specific speech, language, and swallowing difficulties in children with cerebral palsy can be highly useful in drawing substantial conclusions on the presence of particular difficulties to guide better communication and swallowing intervention planning for children with cerebral palsy. ${ }^{15}$

\section{Methodology}

The cross-sectional study design was used for the current study. Data was collected from speech language pathologists working in different hospitals and clinic. The duration of the study was 9 months after approval of synopsis and Ethical approval from IRB. Sample size was calculated on the basis of total population (450) of speech and language pathologists, using $95 \%$ level of confidence and $5 \%$ confidence interval through online calculator. Convenience sampling technique was used and the responses were calculated in persons through emails. Data was collected from speech language pathologists having BS or MS degree in Speech Language Pathology. Diploma holders of Speech Language Pathology PGD(SLP) were included in this study too. Data was taken from SLP's having minimum experience of 1 year and more than 1 year. Speech Therapist dealing with disorders 
other than CP were not considered. Questionnaire was developed by Literature Review and Expert Opinion Using Content Validity Index. Statistical package for social sciences (SPSS) version 23 was used to analyze data. Descriptive statistics was performed to analyzed demographic variables. Categorical data (gender, residency of study participants) was presented as frequency \& percentage. Quantitative variables were presented as mean SD.

\section{Results}

Results of this study consisted of descriptive and inferential statistics. Frequencies and Percentages were taken for demographic variables whereas mean and standard deviation were used for continuous variable.

\begin{tabular}{|c|c|c|c|c|}
\hline \multicolumn{5}{|l|}{ Table I: ???? } \\
\hline Questions & Always & Sometimes & Never & Often \\
\hline $\begin{array}{l}\text { Attention } \\
\text { deficit in CP }\end{array}$ & $\begin{array}{c}48 \\
(22.6 \%)\end{array}$ & $\begin{array}{c}124 \\
(58.4 \%)\end{array}$ & $\begin{array}{c}26 \\
(12.2 \%)\end{array}$ & $\begin{array}{c}14 \\
(6.6 \%)\end{array}$ \\
\hline $\begin{array}{l}\text { Problem } \\
\text { Understanding } \\
\text { Words in CP }\end{array}$ & $\begin{array}{c}83 \\
(39.1 \%)\end{array}$ & $\begin{array}{c}111 \\
(52.3 \%)\end{array}$ & $\begin{array}{c}9 \\
(4.2 \%)\end{array}$ & $\begin{array}{c}9 \\
(4.2 \%)\end{array}$ \\
\hline $\begin{array}{l}\text { Writing } \\
\text { Difficulty in CP }\end{array}$ & $\begin{array}{c}126 \\
(59.6 \%)\end{array}$ & $\begin{array}{c}68 \\
(32.0 \%)\end{array}$ & $\begin{array}{c}3 \\
(1.4 \%)\end{array}$ & $\begin{array}{c}15 \\
(7.0 \%)\end{array}$ \\
\hline $\begin{array}{l}\text { Problem in } \\
\text { Number and } \\
\text { Digits in } \mathrm{CP}\end{array}$ & $\begin{array}{c}55 \\
(25.9 \%)\end{array}$ & $\begin{array}{c}145 \\
(68.3 \%)\end{array}$ & $\begin{array}{c}6 \\
(2.8 \%)\end{array}$ & $\begin{array}{c}6 \\
(2.8 \%)\end{array}$ \\
\hline $\begin{array}{l}\text { Oro facial } \\
\text { Weakness in } \\
\mathrm{CP}\end{array}$ & $\begin{array}{c}184 \\
(86.7 \%)\end{array}$ & $\begin{array}{c}13 \\
(6.1 \%)\end{array}$ & $\begin{array}{c}0 \\
00\end{array}$ & $\begin{array}{c}15 \\
(7.0 \%)\end{array}$ \\
\hline $\begin{array}{l}\text { Articulation } \\
\text { Disorder in } \mathrm{CP}\end{array}$ & $\begin{array}{c}163 \\
(76.8 \%)\end{array}$ & $\begin{array}{c}34 \\
(16.0 \%)\end{array}$ & $\begin{array}{c}0 \\
00\end{array}$ & $\begin{array}{c}15 \\
(7.0 \%)\end{array}$ \\
\hline $\begin{array}{l}\text { Dysarthria in } \\
\mathrm{CP}\end{array}$ & $\begin{array}{c}136 \\
64.1 \%\end{array}$ & $\begin{array}{c}60 \\
28.3 \%\end{array}$ & $\begin{array}{c}2 \\
0.9 \%\end{array}$ & $\begin{array}{c}9 \\
4.2 \%\end{array}$ \\
\hline $\begin{array}{l}\text { Stuttering in } \\
\mathrm{CP}\end{array}$ & $\begin{array}{c}5 \\
2.3 \%\end{array}$ & $\begin{array}{c}89 \\
41.9 \%\end{array}$ & $\begin{array}{c}107 \\
50.4 \%\end{array}$ & $\begin{array}{c}11 \\
5.1 \%\end{array}$ \\
\hline Apraxia in CP & $\begin{array}{c}31 \\
(14.6 \%)\end{array}$ & $\begin{array}{c}135 \\
(63.7 \%)\end{array}$ & $\begin{array}{c}34 \\
(16.0 \%)\end{array}$ & $\begin{array}{c}12 \\
(5.6 \%)\end{array}$ \\
\hline $\begin{array}{l}\text { Hyper nasality } \\
\text { in } \mathrm{CP}\end{array}$ & $\begin{array}{c}30 \\
(14.1 \%)\end{array}$ & $\begin{array}{c}137 \\
(64.6 \%)\end{array}$ & $\begin{array}{c}22 \\
(10.3 \%)\end{array}$ & $\begin{array}{c}23 \\
(10.8 \%)\end{array}$ \\
\hline $\begin{array}{l}\text { Hypo nasality } \\
\text { in } \mathrm{CP}\end{array}$ & $\begin{array}{c}12 \\
(5.6 \%)\end{array}$ & $\begin{array}{c}156 \\
(73.5 \%)\end{array}$ & $\begin{array}{c}27 \\
(12.7 \%)\end{array}$ & $\begin{array}{c}17 \\
(8.0 \%)\end{array}$ \\
\hline $\begin{array}{l}\text { Nasal Air } \\
\text { Emission in } \\
\mathrm{CP}\end{array}$ & $\begin{array}{c}19 \\
(8.9 \%)\end{array}$ & $\begin{array}{c}126 \\
(59.4 \%)\end{array}$ & $\begin{array}{c}12 \\
(5.6 \%)\end{array}$ & $\begin{array}{c}25 \\
(11.7 \%)\end{array}$ \\
\hline $\begin{array}{l}\text { Difficulty in } \\
\text { Chewing Food } \\
\text { in CP }\end{array}$ & $\begin{array}{c}100 \\
(47.1 \%)\end{array}$ & $\begin{array}{c}82 \\
(38.6 \%)\end{array}$ & $\begin{array}{c}6 \\
(2.8 \%)\end{array}$ & $\begin{array}{c}24 \\
(11.3 \%)\end{array}$ \\
\hline $\begin{array}{l}\text { Liquid or Food } \\
\text { Intake in } \mathrm{CP}\end{array}$ & $\begin{array}{c}76 \\
(35.8 \%)\end{array}$ & $\begin{array}{c}113 \\
(53.3 \%)\end{array}$ & $\begin{array}{c}8 \\
(3.7 \%)\end{array}$ & $\begin{array}{c}15 \\
(7.0 \%)\end{array}$ \\
\hline $\begin{array}{l}\text { Cough during } \\
\text { food intake in } \\
\mathrm{CP}\end{array}$ & $\begin{array}{c}33 \\
(15.5 \%)\end{array}$ & $\begin{array}{c}158 \\
(74.5 \%)\end{array}$ & $\begin{array}{c}5 \\
(2.3 \%)\end{array}$ & $\begin{array}{c}16 \\
(7.5 \%)\end{array}$ \\
\hline Difficulty in & 75 & 116 & 0 & 21 \\
\hline
\end{tabular}

\begin{tabular}{lcccc}
\hline $\begin{array}{l}\text { Controlling } \\
\text { food in CP }\end{array}$ & $(35.3 \%)$ & $(54.7 \%)$ & 00 & $(9.9 \%)$ \\
\hline Swallowing in & 77 & 107 & 3 & 25 \\
$\mathrm{CP}$ & $(36.3 \%)$ & $(50.4 \%)$ & $(1.4 \%)$ & $(11.7 \%)$ \\
\hline Drooling in CP & 128 & 55 & 0 & 29 \\
& $(60.3 \%)$ & $(25.9 \%)$ & 00 & $(13.6 \%)$ \\
\hline Saliva Control & 111 & 63 & 0 & 38 \\
in CP & $(52.3 \%)$ & $(29.7 \%)$ & 00 & $(17.9 \%)$ \\
\hline Stucked Food & 65 & 121 & 3 & 23 \\
& $(30.6 \%)$ & $(57.0 \%)$ & $(1.4 \%)$ & $(10.8 \%)$ \\
\hline Difficulty & 69 & 111 & 6 & 26 \\
moving food in & $(32.5 \%)$ & $(52.3 \%)$ & $(2.8 \%)$ & $(12.2 \%)$ \\
CP & & & & \\
\hline
\end{tabular}

The above table illustrate the frequency of different abnormalities in Children with CP. In attention deficit there were $(n=124)$ responded in sometimes and $(n=48)$ participants give response in always category. Problem understanding words in $C P(n=111)$ give response in sometimes $C P$ child have problem in understanding words while $(n=83)$ percipients response on always. $(n=126)$ participants agreed that CP child always have writing difficulty and $(n=68)$ participants were responded on sometimes. The $(n=145)$ participants were responded that sometimes $\mathrm{CP}$ child have problem in number and digit while $(n=45)$ responded on always. There were $(n=184)$ participants agreed that $\mathrm{CP}$ child always have Orofacial weakness while only 15 participants thinks they have most often. There were ( $\mathrm{n}=164$ ) participants agreed that CP child always have articulation problems. The majority of participants reported that $\mathrm{CP}$ child always have dysarthria, chewing problem, saliva control problem and drooling problem. While some participants responded that sometimes $\mathrm{CP}$ child suffer from apraxia, hyper and hypo nasality, nasal air emission, difficulty in moving food, swallowing problem, cough during food intake and liquid food intake problem.

\section{Discussion}

This article expected to gain an insight on the opinion of speech language therapists on the frequency of communication and swallowing disorders observed in children with cerebral palsy through a questionnaire structured on various dimensions of speech, language and swallowing. The results fortified the facts discovered in preceding literature and revealed the nature of difficulties in the various dimensions constituting the questionnaire as supported by majority opinion of speech language therapists. The important articulation features of children with $\mathrm{CP}$ as per electropalatographic studies are unusual tongue-palate contacts, such as double articulation and abnormally retracted articulation. According to the opinions expressed in this study, majority of the speech therapists, more 
than $60 \%$, always found orofacial weakness, articulation disorder, dysarthria associated with cerebral palsy in children which substantiates the previous findings of Nordberg et al'(2012)(16 on speech ability in a population-based study of children with cerebral palsy, in relation to type, motor function, cognitive level and neuroimaging findings. Results showed that more than half of the children under study had a speech disorder or were nonverbal. This also correlates with the 'sometimes' response of over $65 \%$ respondents in current study on the question regarding attention deficit, and word comprehension difficulties, as these particular deficits frequently result in Children with $\mathrm{CP}$ being nonverbal. High frequency of dysarthria as per majority opinion in current study also corroborates the results of the register study of Jackie Parkes et al' (2010) on 17 which proved that such impairments are common in children with $\mathrm{CP}$ and are associated with poorer gross motor function and intellectual impairment. On the question of hyper nasality, hypo nasality, and nasal air emission in Children with $\mathrm{CP}$, over $70 \%$ responded with 'sometimes'. Velopharyngeal dysfunction accounts for the observation of these characteristics and various studies have shown that hypernasality, breathy voice, and change of voice quality are the most common perceptual speech characteristics for the children with spastic CP. Although the number of cases of stuttering in children with $\mathrm{CP}$ is small, stuttering can occur in children with CP. However, above $50 \%$ of the respondent speech therapists were of the opinion that stuttering is never reported as a communication difficulty in children with cerebral palsy. Children diagnosed with cerebral palsy also frequently have difficulties in arithmetic performance and word problem solving compared to the normal peers. In agreement with the previous studies, the results of current study revealed that writing difficulties and problem in number and digits were reported to be sometimes present in Children with CP by more than half of the respondents. However, writing difficulties were reported to be always present by majority of the respondents. Regarding the presence of motor and sensory dysfunction at different levels of deglutition process, majority stated that difficulties in chewing, saliva control and drooling are always noted in Children with CP. These responses of current study on the questions regarding drooling are consistent with the previous findings. In regard to the swallowing difficulties, oral and pharyngeal phase abnormalities are frequently observed in Children with $\mathrm{CP}$ according to the evidence derived from clinical information related to dysphagia in children with cerebral palsy provided by examinations such as video fluoroscopic modified barium swallow. This is evident in the results of current study as well because nearly two-thirds of the respondents expressed that difficulty in controlling food and initiation of swallowing, and stucked food is sometimes observed in the cases of children with cerebral palsy. On the question of cough during food intake, surprisingly the majority, above $70 \%$, responded with sometimes, this finding correlates well with the evidence review of Snider, L., A. Majnemer, and V. Darsaklis' (2011) on ${ }^{8}$ Their review highlighted the risk of aspiration with oral feeding in Children with $\mathrm{CP}$ and its potential pulmonary consequences. However, in evidence review, considerable variability was reported in the nature and severity of swallowing problems in these children with constantly changing needs. This supports the response of majority respondents who chose not to respond with cough being always observed during food intake.

\section{Conclusion}

It is concluded that the Children with $\mathrm{CP}$ have communication and swallowing difficulties associated with impairments in oral motor function, expression and comprehension, and the functioning of oral and pharyngeal swallowing stages in children with cerebral palsy.

\section{References}

1. Reid SM, Carlin JB, Reddihough DS. Distribution of motor types in cerebral palsy: how do registry data compare? Dev Med Child Neurol. 2011;53(3):233-8.

2. Bangash AS, Hanafi MZ, Idrees R, Zehra N. Risk factors and types of cerebral palsy. JPak Med Assoc. 2014;64(1):103-7.

3. Rosen MG, Dickinson JC. The incidence of cerebral palsy. American Journal of Obstetrics and Gynecology. 1992;167(2):417-23.

4. Rogers B, Arvedson J, Buck G, Smart P, Msall M. Characteristics of dysphagia in children with cerebral palsy. Dysphagia. 1994;9(1):69-73.

5. Love RJ, Hagerman EL, Taimi EG. Speech performance, dysphagia and oral reflexes in cerebral palsy. Journal of Speech and Hearing Disorders. 1980;45(1):59-75.

6. Wright R, Wright E, Carson C. Videofluoroscopic assessment in children with severe cerebral palsy presenting with dysphagia. Pediatric Radiology. 1996;26(10):720-2.

7. Damiano DL, Abel MF. Functional outcomes of strength training in spastic cerebral palsy. Arch Phys Med Rehabil. 1998;79(2):119-25.

8. Ito J-i, Araki A, Tanaka H, Tasaki T, Cho K, Yamazaki R. Muscle histopathology in spastic cerebral palsy. Brain and Development. 1996;18(4):299-303.

9. Pirila S, van der Meere J, Pentikainen T, Ruusu-Niemi P, Korpela R, Kilpinen J, et al. Language and motor speech skills in children with cerebral palsy. J. Commun. Disord.. 2007;40(2):116-28.

10. Mysak ED. Neuroevolutional Approach to Cerebral Palsy and Speech. 1968.

11. Blumberg ML. Respiration and speech in the cerebral palsied child. AMA American journal of diseases of children. 1955;89(1):48-53. 
12. Pennington $L$, Smallman C, Farrier F. Intensive dysarthria therapy for older children with cerebral palsy: findings from six cases. Child language teaching and therapy. 2006;22(3):255-73.

13. Allison KM, Hustad KC. Data-driven classification of dysarthria profiles in children with cerebral palsy. Journal of Speech, Language, and Hearing Research. 2018;61(12):2837-53.

14. Otapowicz D, Sobaniec W, Okurowska-Zawada B, Artemowicz B, Sendrowski K, Kułak W, et al. Dysphagia in children with infantile cerebral palsy. Advances in medical sciences. 2010;55(2):222-7.

15. Choi JY, Park J, Choi YS, Goh Y-r, Park ES. Functional communication profiles in children with cerebral palsy in relation to gross motor function and manual and intellectual ability. Yonsei medical journal. 2018;59(5):67785.

16. Nordberg A, Miniscalco C, Lohmander A, Himmelmann K. Speech problems affect more than one in two children with cerebral palsy: S wedish population-based study. Acta paediatrica. 2013;102(2):161-6.

17. Parkes J, Hill N, Platt MJ, Donnelly C. Oromotor dysfunction and communication impairments in children with cerebral palsy: a register study. Developmental Medicine \& Child Neurology. 2010;52(12):1113-9.

18. Snider L, Majnemer A, Darsaklis V. Feeding interventions for children with cerebral palsy: a review of the evidence. Physical \& occupational therapy in pediatrics. 2011;31(1):58-77.

\section{Copyright Policy}

All Articles are made available under a Creative Commons "Attribution-NonCommercial 4.0

International" license. (https://creativecommons.org/licenses/by-nc/4.0/). Copyrights on any open access article published by Journal Riphah college of Rehabilitation Science (JRCRS) are retained by the author(s). Authors retain the rights of free downloading/unlimited e-print of full text and sharing/disseminating the article without any restriction, by any means; provided the article is correctly cited. JRCRS does not allow commercial use of the articles published. All articles published represent the view of the authors and do not reflect the official policy of IRCRC 